\title{
The Development Status and SWOT Analysis of Cultural Industry in Northwest China
}

\author{
Yuxia $\mathrm{Hu}^{1, \mathrm{a}}$ and Haiying $\mathrm{Ma}^{2, \mathrm{~b}^{*}}$ \\ ${ }^{1,2}$ School of Economics, Northwest Minzu University \& The Provincial Key Laboratory of \\ E-commerce of Ethnic Information, Northwest Minzu University, Lanzhou (730124), P.R.China \\ a2253801927@qq.com, blxmahaiying8888@163.com
}

Keywords: Northwest regions; Cultural Industry; SWTO Analysis; Development status

\begin{abstract}
This paper makes an in-depth study of the status and problems of the development of the cultural industry in the northwest region. Based on relevant data and SWOT analysis methods from 2000 to 2013, the status of industry development and opportunities and challenges are analyzed. One basic judgment is that the cultural industry in the northwest has entered a period of rapid development, and the industrial system has begun to take shape but has not yet become a region.
\end{abstract}

\section{Introduction}

Culture Industry is the creation, production and sales of spiritual products and entertainment products that meet the needs of the masses for cultural life. The cultural industry has its own characteristics of culture and industry. Based on rich historical and cultural resources, the cultural industry has inherited national characteristics and values; in terms of industrial properties, it has production, circulation, and consumption. The characteristics of general merchandise are designed to meet the spiritual and recreational needs of the people and produce and reproduce cultural products. The development of the cultural industry will affect the people's production and lifestyle, and thus have an important impact on economic and social development.

Scholars have conducted relevant research on cultural industries from different perspectives. For qualitative research, Liu (2005), Tanzeng (2005) and $\mathrm{Hu}$ (2006) systematically analyzed the development of the cultural industry and constructed the theoretical framework for the study of the cultural industry. Hua (2005) proposed four major capabilities and seven major contents of cultural industry competitiveness, and put forward the strategic focus of enhancing the competitiveness of China's cultural industry. Li (2006) used Anhui Province as an example to construct an evaluation index system of provincial cultural industry competitiveness with three modules, five major elements, and several competitive factors. Hua (2011) pointed out that the core of cultural industry competition is the development of cultural industry clusters, and the key to improving industrial competitiveness lies in the development of various cultural industry clusters.

This paper focuses on the development status and comprehensive competitiveness of the cultural industry in the northwest region. Based on related data and SWOT analysis methods, it presents the development status of the northwestern region's cultural industry. The paper assesses the regional development status and competitive rankings and analyzes the difficulties in the development of the cultural industry in the northwest region, and in the last section, we discuss the conclusions and corresponding policy recommendations.

\section{The Development Status of Cultural Industry in Northwest China}

Under the background that the cultural industry has been promoted to the national strategy, the five northwestern provinces with rich cultural resources are also focusing on the development of cultural industries, providing a strong driving force for regional economic growth. 


\section{Basic Judgment of the Industrial Development}

The Unique National Cultural Resources as the Basic Preconditions for the Development of the Cultural Industry. The Northwestern region has a unique geographical climate, natural resources and a long history of diverse ethnic and cultural resources. The richness of natural ecology has nourished the diversity of production and lifestyle. Farming, nomadic, semi-agricultural, semi-agricultural, hunting, and other production methods have resulted in the compatibility of farming civilization, nomadic civilization, and hunting civilization in the northwest region. In the northwestern region, ethnic minorities such as Han and Hui, Mongolian, Uygur, and Kazak are living together. The cultures of various ethnic groups add up to each other, forming distinctive regional living customs and folklore cultures, as well as folk stories and myths and legends handed down from generation to generation. In addition, as a hot spot for China's revolution and construction, there are numerous old revolutionary bases in the region, rich in human and cultural resources, and the natural landscape and cultural heritage of the region jointly build the foundation for the development of the cultural industry.

The Cultural Industrial System has not yet formed a Regional Pillar Industry. In recent years, the total income of the institutions affiliated with cultural relics departments in the northwest has always maintained a rapid growth. After more than 10 years of development, the total revenue increased from 926 million Yuan in 2000 to 13.254 billion Yuan in 2011, an increase of More than 10 times, the growth momentum is good. It can be seen that under the guidance of industrial policies and structural reforms, the cultural industry in the northwest region has passed the initial stage and entered a period of rapid development. The industrial growth rate is much higher than the GDP growth rate over the same period.

Although the cultural industry in the northwest region has begun to take shape, but the added value of the cultural industry accounts for a relatively small proportion of GDP, is still less than 5\% of the pillar industry measurement standards, has not yet developed into a regional support industry, with a larger industrial growth space.

Increasing Government Supports and Improved Industrial Policy Environment. Since 2007, per capita cultural expenditures in the northwestern provinces and regions have grown rapidly and steadily. In 2013, the per capita cultural expenditures in Shaanxi, Gansu, Qinghai, Ningxia, and Xinjiang were $9.77,24.23,11.40,8.96$ and 2000 respectively. The local government's support for the cultural industry has continued to increase. The cultural industry policy support environment in the northwest region has been increasingly perfected. What needs to be concerned is that policy support is negatively related to the level of regional cultural industry development. In the five provinces and regions of the Northwest, the per capita cultural undertaking fee in Shaanxi Province is relatively low, while Qinghai and Ningxia have the greatest policy support.

The Obvious Regional Differences in Investment in Cultural Industry Infrastructure. In terms of investment in cultural infrastructure construction, in addition to Qinghai Province, the actual completion of basic investment in the current cultural undertakings in the other four provinces and autonomous regions has doubled compared to 2000, of which Shaanxi and Ningxia regions have The growth of investment in cultural infrastructure was rapid, and the investment in 2013 was 60 times and 50 times that in 2000, respectively. In terms of absolute investment level, Xinjiang and Gansu actually achieved a basic investment of more than 140 million Yuan in 2013 in cultural undertakings. Qinghai Province has a long way to go in terms of investment growth rate and absolute value.

Compared with the infrastructure investment in the cultural industry, the number of employees in the five provinces in the northwest remained generally stable, but the differences in investment in human resources in the cultural industries between provinces and regions were even more significant. Among the five provinces and regions, employees in Shaanxi Province have an absolute advantage. Although the number of personnel has decreased in recent years, the number of artist's performing arts groups has remained at around 7,000. The number of employees in the two provinces of Gansu and Xinjiang ranks in the middle and shows a steady upward trend. The number of artist's performing arts groups is about 5,000; the number of employees in Qinghai and Ningxia is significantly lower, and the number of artist's performing arts groups has remained at around 1,000. Resources need to increase. 


\section{SWOT Analysis of Cultural Industries}

Advantages. On the one hand, the northwest region has unique natural scenery and deep cultural heritage. The northwestern region is vast in area, rich in topography and landforms, with plains and mountains, lakes and lakes intertwined, boasting natural and beautiful natural scenery. At the same time, the prairie, neighbors, deserts, and snow-capped mountains are unique. The flora and fauna resources are rare and exotic and have diversified industrial values for development. The northwest region has a strong historical and cultural heritage. The Qin Shihuang Terracotta Warriors and Horses, Dunhuang Mogao Grottoes, Western Xia Imperial Tombs, and the ancient Loulan Kingdom have become historical and cultural heritages that have made the world famous. From the ancient capital of Xi'an in the 13th to the ancient capital of Xi'an, the northwest region formed the Silk Road on the road of cultural and trade exchanges between China and the West through the Hexi Corridor, Gansu and Xinjiang, and Central and West Asia. The Chinese Red Army's long march to Qinghai, Gansu, Ningxia, and Shaanxi formed a revolutionary cultural zone.

On the other hand, ethnic folk customs are diverse and religious beliefs are strong. The natural environment and living customs in the northwest region have created the Loess Plateau culture, grassland culture, Islamic culture, Western-style culture and part of Tibetan culture. Different cultures have unique and distinctive styles. The inhabitation of ethnic minorities has preserved folk arts such as ancient music, opera, and embroidery, and has become a living fossil of ethnic culture, with potential industrial development value. Northwest is located in the frontier. Arab Islam and Indian Buddhism spread from here to China. Qinghai and Gansu Provinces have preserved a large number of Tibetan Buddhism temple sites such as the Ta'er Monastery and Labrang Monastery. In the Xinjiang region, they have Artemis. The famous mosques, such as the mosque, Shaanxi Daisi, Baisila Temple, and Kuman Temple, have a large number of religious professionals and have a strong religious atmosphere.

Disadvantages. First of all, the industrial concept is behind. The northwestern region pays more attention to its spirituality to culture, ignoring its commodity nature, paying more attention to the public welfare of cultural work, and ignoring its proper operation. For the lack of differentiation between cultural undertakings and cultural industries, compared to the public welfare of cultural undertakings, the cultural industry should pay more attention to the operation, and seek industrial efficiency through market-oriented operations. Second, there are not enough professionals. The cultural industry requires professionals in many fields such as cultural studies, appreciation and protection, and cultural development. However, the shortage of professionals in the northwest region has led to a lack of attractiveness for talents and serious brain drain. Finally, brand awareness is poor. Although the region has rich natural and historical humanities resources, it has not formed strong brand awareness, and residents have insufficient awareness of the northwest tourism and cultural industries.

Opportunities. First, the high level of attention of the central high-level government to the cultural industry under the "New Normal" has enabled the cultural industry to have greater growth potential. The improvement of the overall national strength and the improvement of the residents' material living standards have driven the market demand for cultural products, which has greatly expanded the industrial development space. Second, since the implementation of the strategy for the development of the western region, the driving force for economic development in the northwest region has increased and the economic benefits have continued to increase. This has laid a good economic environment for the development of the cultural industry. The preferential policies for the development of the western region also contribute to the rapid rise of the cultural industry. Third, the One Belt, One Road to all-dimensional development construction pattern can break through administrative divisions and industrial divisions, which will help improves the international vision of the cultural industry in the northwest and promotes regional cultural exchanges and industrial integration. It provides new opportunities for development. Fourth, the development of information technology and the acceleration of the process of global economic integration have led to a gradual increase in the number of cultural exchanges between countries around the world and an accelerating pace.

Threats. On the one hand, the economic foundation is weak. The northwestern region is deep inland, and its regional economic foundation is weak, and its location has poor traffic conditions. The 
development of the cultural industry depends on the support of the regional economy. The weak economic situation has led directly to the lack of investment in the cultural industry, which seriously restricts the development of the cultural industry in the northwest. On the other hand, the involvement of new technologies in cultural resources can enhance industrial development, but at the same time it may damage the originality of resources and lead to the collapse of some non-renewable resources. The protection of culture while doing industry development is a major threat to the development of the industry.

\section{Problems in the Development of Cultural Industry in Northwest China}

Location Disadvantage Restricts the Development of Cultural Industries. The economic foundation for the development of the cultural industry in the northwest is relatively weak. In 2014, the gross national product of the five provinces in the northwest totaled 3.88 trillion Yuan, accounted for $6.1 \%$ of the GDP. Not only was it lagging behind in the eastern and central regions, but also far from the southwest. The level of economic development has limited the investment in infrastructure, talent, and technology required by the cultural industry. At the same time, the income level of residents in the northwest region is low. In 2014, GDP per capita was lower than the national average except for Shaanxi Province, and residents' income limited the demand for cultural industries. Insufficient Industrial Input and Output. Compared with the major provinces of the domestic cultural industry, the added value of the northwest cultural industry is less than 5\% of GDP, which is far from constituting the pillar industries of the regional economy. Even though the northwest region has natural natural and humanistic resources, the backward industrial development has restricted the transformation of cultural resources and the cultivation of cultural markets. At the same time, the lack of output in the cultural industry and the still-to-be-added industrial input such as manpower and infrastructure are the key reasons behind the backwardness of the comprehensive competitiveness of the northwest region. Increased industrial investment and optimized input structure can drive industrial output growth. In recent years, the actual completion of basic investment in the cultural industry in the northwest region has continued to grow, but it has lagged far behind the eastern region in the degree of infrastructure improvement.

Lacking of Competitive Institutional Environment. The inland areas of the northwestern region are lacking in the perception of the market and modern civilization. Although the market economy system has already begun to be implemented, the implementation of the planned economy takes a long time in most regions. The impact of the existing planned economy thinking has led to the development of the region. Relying on the government, the development of cultural industries lacks autonomy and enthusiasm. At the same time, the low degree of marketization is also an important factor that restricts the development of the cultural industry in the northwest region. The cultural sector in the northwest is generally small in business scale, there are few cultural enterprises with brand competitiveness, and the degree of industrial marketization is poor, and it has not been built into benign development. The lack of understanding of the concept of the cultural industry in the region, the lag in cultural system reform, the difficulty of private capital entering the core cultural industries, and the constraints on the supply of funds for industrial development are not conducive to the allocation of resources to market mechanisms.

Low Level of Regional Linkage. The northwest region has rich cultural resources but relatively low concentration density. The dispersed resources are not conducive to the joint development of cultural industries and the overall development of regional culture. At the same time, the propaganda of the cultural industry in the northwest region is insufficient. Most people's impressions of the northwest remain far away, poverty and mystery. Although different provinces and regions have their own unique cultural image, they lack the integrated regional image. In order to benefit from the advantages of cultural resources, the historical advantages of the Silk Road and the development opportunities brought about by the Belt and Road Initiative have not yet exerted a positive effect. 


\section{Conclusions and Policy Implications}

This paper first analyzes the opportunities and challenges of the development of the cultural industry in the northwest region based on the data and SWOT analysis methods of the cultural industries in the northwest from 2000 to 2013. Then it constructs the industrial evaluation index system and uses the principal component analysis method to compare the provinces and regions in the northwest. The comprehensive competitiveness of the cultural industry has found that the comprehensive ranking of regional industrial development has lagged behind, and the development of the cultural industry among the various provinces and regions within the region has a significant non-equilibrium. Finally, the problems existing in the industrial development are discussed. In addition, it is still necessary to strengthen inter-provincial communication and exchanges, break ethnic and religious segregation, and take the One Belt and One Road strategy as an opportunity to implement the establishment of the Strategic Alliance for Cultural Development of Five Provinces and Five Provinces in Northwest China set up in 2014. The region strives for the nation's supportive policy for the cultural industry in the northwest, integrates the overall image of the cultural industry in the "Silk Road" in the northwest, builds a coalition of cultural industries in the northwest, promotes the exchange of regional culture, and forms a joint force for cultural industry development.

\section{Acknowledgements}

This work is supported by The Funds of Central University of Northwest Minzu University (Grant No: 31920170059) and by the Provincial Key Laboratory of E-commerce of Ethnic Information of Northwest Minzu University and Comprehensive experimental teaching center in Economics (Grant No. 2016XJSYJXSF2X-01-10019109).

\section{References}

[1] Liu Jifa, Cultural Industry, Economic Management Press, (2005).

[2] Dan Zeng, Cultural Industry Development Theory, People's Publishing House, (2005).

[3] Hua Jian, Connotation, Structure and Strategic Emphases of Cultural Industry Competitiveness, Journal of Peking University: Philosophy and Social Sciences, 2 (2005) 9-16.

[4] Ma Yi, Wang Lu, Study on the Development of Cultural Industry in China, Macroeconomic Research, 8 (2007)38-44.

[5] Hua Jian, Cultural Industry Cluster Development, Shanghai People's Publishing House, (2011).

[6] Ma Yi, Zheng Shilin, A review and prospect of the research on regional cultural industry efficiency in China, Economics Dynamics, 3(2010)83-86.

[7] Wang Family, Zhang Rong, Research on the efficiency of cultural industries in 31 provinces and cities in China based on the three-phase DEA model, China Soft Science, 9 (2009) 75-82.

[8] Jiang Ping, Wang Yong, Research on Input and Output Efficiency of Full-caliber Chinese Cultural Industry: An Analysis Based on Three-phase DEA Model and Super-efficiency DEA Model, Journal of Quantitative Economics and Technology, 12 (2011)69 -81. 